\title{
El icono en la doctrina de signos*
}

\author{
Thomas A. SEBEOK \\ Traducción de Oscar Gómez
}

1. Se dice que un signo es icónico cuando hay una similitud topológica entre un significante y sus denotata.

1.1. Fue en 1867, en su artículo "Sobre una nueva lista de categorías", cuando Peirce publicó por primera vez su ahora famosa tríada fundamental, afirmando, inicialmente, que había tres tipos de signos (o, como él los llamó entonces, 'representaciones'): (a) semejanzas (un término que pronto abandonó en favor de icono), o "aquellos cuya relación con sus objetos es una mera comunidad en alguna cualidad"; (b) índices, o "aquellos cuya relación con sus objetos consiste en una correspondencia en el hecho"; y (c) símbolos (que son lo mismo que los signos generales), o "aquellos cuya relación de base con sus objeto es una cualidad imputada", que más tarde llamaría "leyes", refiriéndose a convenciones, hábitos o disposiciones naturales de su interpretante, o del campo de su interpretante.

1.2. Peirce (2.277) distinguió más tarde tres subclases de iconos: las imágenes, los diagramas, y las metáforas. La noción de icono - que está fundamentalmente vinculada al proceso platónico de la mímesis, y que Aristóteles (en Poética, IV) amplió desde la representación fundamentalmente visual hasta abarcar toda experiencia cognitiva y epistemológica - ha sido objeto de numerosos análisis en sus diversas variedades y manifestaciones, aunque, sin embargo, todavía quedan cuestiones teóricas por responder. Las imágenes (que a veces, y de manera simplificadora, se consideran todavía equivalentes a todos los iconos, o lo que es peor, se asumen de manera ingenua como limitadas únicamente a la esfera visual) fueron estudiadas en dos investigaciones excepcionalmente profundas de Eco (1972) y M. Wallis (1975: capítulo 1) respectivamente. En cuanto a la teoría de los diagramas,

\footnotetext{
* Nota del traductor: Esta traducción corresponde a un texto de Sebeok, inédito en castellano, que apareció en 1976 como parte de la obra intitulada Contributions to the Doctrine of Signs (Bloomington-Lisse, Indiana University Press/Peter de Ridder Press, pp.128-131). Una versión ulterior y reducida del mismo la encontramos en Sebeok, Th. A. (1994), Signs: An introduction to semiotics (University of Toronto Press), cuya traducción al castellano, Signos: una introducción a la semiótica, se publicó en Paidós en 1996.
} 
esta ocupaba buena parte de las investigaciones semióticas de Peirce, y ha sido ahora revisada cuidadosamente por Zeman (1964), Roberts (1973), y Thibaud (1975) en algunas de sus principales ramificaciones, que incluyen la teoría de grafos moderna. Peirce no continuó el antiguo recurso retórico de la metáfora, aparte (pese a la crítica de Todorov ${ }^{1}$ ) de designarla correctamente, en su lista de categorías, como icono. Las funciones icónicas del lenguaje también han sido objeto de un buen número de revisiones últimamente, como por ejemplo, por Jakobson (1965), Valesio (1969) y Wescott (1971).

1.3. A pesar de la vasta literatura, siempre en aumento y por lo general útil, para avanzar en nuestra comprensión del icono, aún persisten varios problemas teóricos serios. Dos de ellos, que podemos llamar el problema de la simetría y el de la regresión, merecen nuestra atención al menos brevemente; otros han sido discutidos por Eco (1972 y 1976: 190-217) de manera muy interesante y consistente, aunque sin resultados definitivos.

1.3.1. Wallis, por su parte, siguiendo la costumbre, afirma ex cathedra que "la relación de representación es asimétrica: un signo icónico o un signo convencional aislado representa a su representatum pero no al revés" (1975: 2). Permítanme hablar ahora de una foto de una reproducción de una pintura famosa, por ejemplo, La Gioconda, como un signo icónico, o imagen, ya que la copia, que de esta manera se convierte en el denotatum (o representatum), es al mismo tiempo un signo icónico en sí misma en relación al retrato original que cuelga en el Louvre, su denotatum; pero esta pintura, además, es un signo icónico para el modelo de Leonardo, la mujer conocida como Mona Lisa, su denotatum. En esta secuencia diacrónica, Mona Lisa está primero, su retrato después, a continuación, su reproducción, y, finalmente, una fotografía de esta. Obsérvese, sin embargo, que no hay nada en la definiciones (de iconicidad) propuestas anteriormente (3.3 o 3.2) que requieran la imposición de ningún tipo de prioridad cronológica: la definición de Peirce habla de "una mera relación con alguna cualidad", y la que se propuso al inicio de esta sección, únicamente de "una similitud topológica", pudiendo aplicarse ambas cualidades tanto hacia atrás como hacia delante. ¿Es simplemente una convención no motivada asignar una secuencia temporal progresiva a la relación entre significante y significado? Esta dificultad tal vez pueda conducirse por medio del siguiente ejemplo: supongamos que un renombrado personaje contemporáneo, como el Papa, que me es conocido - como lo es para la mayoría de los católicos - únicamente a través de su fotografía, o algún otro tipo de representación pictórica, pero que un día, tengo la oportunidad de verlo en carne y hueso; en esa ocasión, el Papa vivo se convertiría para mí en "signo icónico" debido a su imagen tan familiar, su denotatum fotográfico o litográfico (Peirce, por supuesto, no veía nada extraño en que un ser humano fuese en sí mismo un signo; cf. 5314, y 6344). Este problema no es desconocido para los

\footnotetext{
1 Todorov defiende que "el icono es más una sinécdoque que una metáfora. No puede decirse, por ejemplo, que un punto negro se asemeja al color negro". Sin embargo, la sinécdoque, como cualquier otra metonimia, pertenece claramente a la categoría de los signos indiciales, comprendido en su definición. Por lo tanto, se puede decir que un punto negro constituye una muestra del color negro.
} 
etólogos tampoco. Así, Konrad Lorenz aludió a esto en su observación de que "la forma de la pezuña de un caballo es tanto una imagen de la estepa que pisa, como la impresión que deja es una imagen de la pezuña" (Introducción a Wickler 1968: xi). Si este atributo de reflexividad puede probarse como una propiedad característica e indispensable de los iconos, entonces seguramente la flecha del tiempo deba ser incorporada en la revisión de las definiciones existentes.

1.3.2. En cuanto al vertiginoso problema de la regresión, que sea ilustrado con el siguiente ejemplo: un bebé puede considerarse como un signo con respecto a su madre si hay una similitud topológica entre el bebé, como significante, y su madre, su denotatum. Sin embargo, la niña puede del mismo modo, aunque sin duda en menor grado, presentarse como un signo icónico de su padre, de cada uno de sus hermanos, de todos sus parientes, y, aún más, de todos los miembros de la raza humana, así como de todos los primates, e incluso, de todos los mamíferos, todos los vertebrados, y demás, y así sucesivamente, en un interminable retroceso hacia denotata cada vez más generalizados. Esta peculiaridad del signo icónico merece consideraciones mucho más cuidadosas de las que podemos ofrecer aquí, en parte por razones de lógica, en parte para iluminar las bases psicológicas de sus considerables, al ser vicarios, poderes mágicos y evocativos, algunas de cuyas implicaciones para la conducta y la historia de la cultura han sido tratadas por Wallis (1975: 15-17).

1.4. Hay muchos casos de iconicidad en el discurso animal (para una discusión sobre los iconos genotípicos véase Gregory Bateson, en Sebeok, 1968: 614 y ss.), que implican prácticamente a todos los canales disponibles como el químico, el auditivo o el visual. La función icónica de una señal química está bien ilustrada por la sustancia de alarma que segrega la hormiga Pogonomyrmex badius: si el peligro para la colonia es momentáneo, la señal (la cantidad de feromona liberada) se desvanece rápidamente dejando a la mayor parte de la colonia inalterada. A la inversa, si la amenaza persiste, la sustancia se propaga, e implica la participación de un número cada vez mayor de trabajadoras. El signo es icónico en la medida en que varía en proporción análoga al aumento o disminución de los estímulos de peligro (Sebeok, 1972: 95).

El comportamiento de ciertas audio-mímicas de los véspidos ilustra la función icónica de una señal auditiva. Así, la mosca Spilomyia hamifera Lw. muestra un ritmo de aleteo de 147 golpes por segundo mientras revolotea cerca de la avispa Dolichovespula arenaria F. (a la que también se asemeja en el patrón de color). Dado que esta avispa vuela con 150 golpes por segundo, se supone que los dos sonidos de vuelo son indistinguibles para los depredadores, y las aves cazadoras de moscas son así engañadas (Sebeok 1972: 86).

Por último, un elegante (aunque a veces controvertido) ejemplo de una compleja muestra de comportamiento que se desarrolló, por así decirlo, hasta funcionar como un signo icónico visual es el descrito gráficamente por Kloft (1959): el extremo trasero del abdomen de un áfido, y la forma de mover sus patas traseras, constituye para una hormiga obrera un vehículo sígnico compuesto, que interpreta como la cabeza de otra hormiga y el movimiento de sus antenas. En otras palabras, se pre- 
tende que la hormiga identifique la semejanza (el extremo trasero del áfido) con su denotatum (la parte delantera de una hormiga) y que actúe a partir de esta información, a saber, tratar al áfido como una efigie (una subespecie del icono).

\section{BIBLIOGRAFÍA}

Eco, Umberto (1972), "Introduction to a Semiotics of Iconic Signs" en VS: Quaderni di Studi Semiotici 2, pp. 1-15.

- (1976), A Theory of Semiotics, Bloomington, Indiana University Press.

JAKOBSON, Roman O. (1965), "Quest for the Essence of Language", en Diogenes 51, pp. 21-37. KLOFT, Werner (1959), "Versuch einer Analyse der Trophobiotischen Bezie hungen von Ameisen zu Aphiden”, en Biologische Zentralblatt 78, pp. 863-870.

Peirce, Charles S. (1935-66), Collected Papers, C.Hartshorne, P.Weiss, and A.W.Burks, eds., Cambridge, Mass., Harvard University Press.

Roberts, Don D. (1973), The Existential Graphs of Charles S. Peirce, The Hague, Mouton. SEbeok, Thomas A., ed., (1968), Animal Communication: Techniques of Study and Results of Research, Bloomington, Indiana University Press.

- (1972). Perspectives in Zoosemiotics, The Hague, Mouton.

ThiBaud, Pierre (1975), La logique de Charles Sanders Peirce: Del'algebreaux graphes. Aix-en-Provence, Universite de Provence.

VALEsio, Paolo (1969), "Icons and Patterns in the Structure of Language", en AC Acts ofthe International Congress of Linguistics II (Bucharest) 10, pp. 383-387.

WaLlis, Mieczyslaw (1975), Arts and signs. Lisse-Bloomington, Peter de Rider Press/Indiana University Press.

Wescott, Roger W. (1971), “Linguistic Iconism”, en Language 47, pp. 416-428.

WiCKLER, Wolfgang (1968), Mimicry in Plants and Animals, NewYork, McGraw Hill.

Zeman, Jay J. (1964), The Graphical Logic of C.S. Peirce. Dissertation, University of Chicago.

\section{RESUMEN}

Texto legendario sobre categorías fundamentales de la semiótica.

Palabras clave: iconos, teoría de la información, semiótica.

\section{The Icon in the Doctrine of Signs}

\section{ABSTRACT}

Legendary contribution about fundamental cathegories of Semiotics.

Keywords: icons, information theory, semiotics.

\section{RÉSUMÉ}

texte légendaire sur les cathégories fondamentales de la sémiologie. 